\title{
Agent-Based Modelling of Pragmatic Legitimacy as Organizational Conflict Control
}

\author{
Marvin S. Daguplo ${ }^{1}$, Marilou L. Masing ${ }^{2}$, Max Teody Quimilat ${ }^{3}$ \\ ${ }^{1,2,3}$ College of Teacher Education, Southern Leyte State University, Philippines
}

\begin{abstract}
Pragmatic legitimacy drives the organization to minimize conflicts by increasing the felt need satisfaction of employees. As a conflict control, Pragmatic Legitimacy Model (PLM) is anchored on the premise that organizational behaviours are desirable within socially constructed system that caters employees' interests. An adaptation of Joshua Epstein's Model of Civil Violence (2002) reflected as Rebellion Model in Netlogo v. 5.2.1, the model-simulation depicts that the strength of the pragmatic legitimacy does not depend only on the number of employee who are satisfied but on the degree on which the organization was able to control that complex need of each employee which leads to their satisfaction. Thus, for pragmatic legitimacy to be beneficial, the organization must direct less in specific benefits for an individual employee and, instead, more responsive to the employees' larger interest.
\end{abstract}

Keywords: ABMS, satisfaction, conflict-control, employees' felt needs, theory development, social science

\section{INTRODUCTION}

Pragmatic legitimacy is considered as a central concept in an organizational control. It has become one of the most cited theories in organizational arena (Tilling, n.d., Deegan, 2002; Deegan et al., 2002; Milne and Patten, 2002; Cho and Patten, 2006)) more particularly on organizational development and cooperation (Brinkerhoff, 2005). In fact, it has long been recognised as a core element in political and governance regimes, dealing with the relationship between societal acceptance of regimes and institutions and their ability to exercise power and authority effectively (Brinkerhoff, 2005; Weber, 1947) making it a license that operates for an organization to survive in a society (Chung, 2010).

Organizational theory suggests that organizational survival depends not just on material resources and technical information, but also on the organization's perceived legitimacy (Powell \& DiMaggio, 1991). As a critical feature in organizational survival, organizational legitimacy has been explored through a diverse range of theoretical lenses, including institutional theory (Ruef \& Scott, 1998; Scott, Ruef, Mendel, \& Caronna, 2000), resource dependency theory (Pfeffer \& Salancik, 1978), organizational ecology (Aldrich, 1979; Aldrich \& Marsden, 1988; Hannan \& Freeman, 1989), and building organization-public relationships (Patel, Xavier, \& Broom, 2005).

From its vague beginning, legitimacy has expanded its scope to sociology (Kumar \& Sunan, 2008), political science (Zeldith, 2001), organizational management (Hegtvedt, 2004), business (Etzioni, 1987) and social interaction (Kelman, 2001). All these domains consider legitimacy, despite its vague characteristics, as a constant exchange of relationship between the organization and its constituents, a guiding force that direct and redirect the movement of an organization. Hence, the level of congruence between corporation's activities and expectations of that particular corporation's activities (see O'Donovan, 2002) is a direct reflection of its legitimacy. As Suchman (1995) stressed, managers can build a legitimacy reservoir through frequent and intense communication with the organizations' constituents and surroundings.

All these literatures suggest that "legitimacy should always be considered as a part of the emerging vocabulary of public relations scholars and practitioners as the discipline focuses more on relationship management" (Heath, 2001). However, despite all these claims on the importance of legitimacy in an organizational survival, less exploration were made that develop an account on how to control organizational conflicts as an inclusive entity that shows organizations' legitimacy. In fact, Patel, Xavier, \& Broom (2005) recommended that a study should be conducted on the effect of legitimacy at different points in an organization's lifecycle (ie. researchers could consider how different type of legitimacy handles violence). This study, therefore, aims to develop a computation model based on the role of pragmatic legitimacy as a tool to control conflict or violence within the organization. 


\section{Model Description}

\section{MODEL DEFINITION}

This Model on Pragmatic Legitimacy as an organizational conflict control is anchored on the premise that organizational behaviours and actions are desirable, proper, or appropriate within some socially constructed system of norms, values, beliefs, and definitions and of an individual's interests (Micro-level organizational Legitimacy). It acknowledges the idea that legitimacy relates to the instrumental value of the organisation in terms of how it fulfils the interest of its constituents (Pragmatic Legitimacy) The model further believes that organizations respond to their environment through the exchange of information. The exchange of information within a system will cause adjustment in both system structures and processes (Cutlip et al, 2000).

\section{Model Assumptions}

Given that both employees and communication are central to organizational legitimacy this paper borrows the following empirical principles:

- Employees behaviours are enacted in and through environmental influences and processes (Cutlip et al., 2000)

- Communication of such environmental influences and processes can lead to organizational adjustment and adaptation (Cutlip et al., 2000; Everett, 2001)

- Employees behaviours are enacted in and through organizational adjustment and adaptation (H. Aldrich, 1999; Buysse \& Verbeke, 2003; Cutlip et al.,2000; Everett, 2001; Heugens et al., 2002)

- Communication of such organizational adjustment and adaptation can lead to organizational legitimacy (Dowling \& Pfeffer, 1975; Suchman, 1995).

Thus, this study offers the following assumptions:

Assumption 1: Agent in an organization has basic needs that the organization must meet.

Assumption 2: Pragmatic Legitimacy defines the strength of the organization to meet the needs of its employees.

Assumption 3: Display of employees' behaviour and felt-need through regular communication maximize the achievement of pragmatic legitimacy.

Assumption 4: Adjustment of organizational procedure in response to employees behaviour optimize organizations' achievement of pragmatic legitimacy.

Assumption 5: Employees' behaviours are influenced and/or sustained by organizational change.

Guided by these assumptions, this paper simulates how pragmatic legitimacy is instrumental in attaining and/or sustaining employees' satisfaction by controlling or minimizing conflict in the organization.

\section{Model Parameters}

This study is an Adaptation of Joshua Epstein's Model of Civil Violence (2002) reflected as Rebellion Model in Netlogo v. 5.2.1 (Wilensky, 2005). The model involves two major categories of actors:

"Agents" are members of the general population, in this study proportion of the rank and file employees of the organization, and may be actively rebellious or not. Epstein (2002) stressed that conflict (C) or violence in the system can be defined by two important components he called hardship (H) and legitimacy (L) and functionally related as:

$G=H(1-L)$; theoretically redefined in this study as $C=N(1-P P L)$.

"Cops"' are the forces of the central authority, who seek out and arrest actively rebellious agents. In this study, proportion of employees with administrative function and are considered alter-ego of the central authority in their respective offices.

Other parameters include:

"Vision" - Number of lattice positions that the cop is able to inspect. In this study the proximity of the supervisor to the subordinates which affects the recognition of motives or acts of conflicts of the rank and file employees. Closer proximity provides higher chance of communication and/or identification of motives of conflicts.

"Government Legitimacy" - a generalized perception or assumption that the actions of an entity are desirable, proper, or appropriate within some socially constructed system of norms, values, beliefs, and definitions. In this study, it is the extent to which the organisation can act to serve the needs and interests of its constituents (Pragmatic Legitimacy). Thus, employees' felt need satisfaction (satisfied, moderately satisfied, not satisfied) defines legitimacy of the organization. 
"Jail Term" - A random number in which the agent is arrested. This refers to the number of disciplinary move of the administration to control motive/acts of conflicts.

From these parameters, the model will determine the degree of which pragmatic legitimacy (in \%) can control or reduce number of employees who are actively involved on conflicts within the organization, thus, increasing the number of employees with high satisfaction level.

\section{SCENARIOS FROM THE MODEL}

Scenarios of the model-simulation is reflected according to the degree of perceived pragmatic legitimacy implemented by organizations which can possibly be equated to Webbers' (1978) types of authority - charismatic, traditional, and legal-rational - each of which corresponds to a brand of leadership that is operative in contemporary society.

The model-simulation result for $90 \%$ pragmatic legitimacy revealed that $100 \%$ of the employees were satisfied to the central authority of the organization. This degree of pragmatic legitimacy in an organization expressed an authority which can be considered extraordinary for exerting effort to cater the needs of the organizations' constituents which happens when employees give their massive trust and unbreakable faith to their authority who manages the organization that provides their needs (Maboloc, 2015). This degree of pragmatic legitimacy convenes diverse and conflict-prone people behind the organization (Maboloc, 2015) reducing the probability of developing conflicts. As evident in table 1, no employees were not satisfied.

The $90 \%$ pragmatic legitimacy, however, can be problematic because it is somehow based on some form of messianic promise providing its employees or constituents almost all their needs. Extreme case of this leads to the personalization of power which can be mistakenly confused with engineered idolatry to central authority. This what makes this degree of pragmatic legitimacy unstable. Yes, it zero-down conflicts, but its practice make it short-lived (Weber, 1978) to the extent that the central authority loses its power of control needs overtaking legitimacy (Dogan in Hawkesworth \& Kogan 2002).

Table 1: Simulation results for $90 \%$ organization pragmatic legitimacy

\begin{tabular}{|c|c|c|c|c|c|c|c|c|c|c|c|}
\hline Conflict & \multicolumn{9}{|c|}{ Trial } & \multirow{2}{*}{ Average } \\
\cline { 2 - 13 } Involvement & $\mathbf{1}$ & $\mathbf{2}$ & $\mathbf{3}$ & $\mathbf{4}$ & $\mathbf{5}$ & $\mathbf{6}$ & $\mathbf{7}$ & $\mathbf{8}$ & $\mathbf{9}$ & $\mathbf{1 0}$ & \\
\hline Less & 480 & 480.0 & 480.0 & 480.0 & 480.0 & 480 & 480 & 480 & 480 & 480 & 480.0 \\
\hline Moderate & 0 & 0.0 & 0.0 & 0.0 & 0.0 & 0 & 0 & 0 & 0 & 0 & 0.0 \\
\hline High & 0 & 0.0 & 0.0 & 0.0 & 0.0 & 0 & 0 & 0 & 0 & 0 & 0.0 \\
\hline
\end{tabular}

The simulation results for $75 \%$ pragmatic legitimacy (Table 2) illustrates presence of central authority that can be considered as a legitimacy established based on tradition or order. The model simulated at $75 \%$ pragmatic legitimacy shows that majority of the employees have less chance to be involve in comflict $(\mathrm{M}=473.9)$ but, as noticed, presence of employees who are moderately into conflict $(\mathrm{M}=5.0)$ and are into actual conflict $(\mathrm{M}=1.2)$ are now evident. A number of employees whose felt need are not met can now be considered as minimal threat to conflict. This happens because, unlike the $90 \%$ pragmatic legitimacy where felt needs are taken care by the central authority, response to needs and distribution of resources is now associated with the organization's tradition and order which is based on some norms and practices. Here, pragmatic legitimacy had its reference to its connection to the past and justifies its actions by claiming that they conform with precedents (Coleman, n.d.).

History illustrates cases of these degree of pragmatic legitimacy. "As the ancients taught us," "As our originating sacred document declares," "As the founding fathers saw" are typical motifs and appeals of this pragmatic legitimacy. As we will see, traditional forms of authority never fully fade away. All authority rests on some variant of tradition or gets related back to it (Coleman). This leads to an organizations' legitimacy where central authority may suffer from a lack of regularity in the creation of legal standards (Maboloc, 2015). This lack of moral regularity creates few feeling of dissatisfaction among employees' felt need as evident in Table 2.

Table 2. : Simulation results for $75 \%$ organization pragmatic legitimacy

\begin{tabular}{|c|c|c|c|c|c|c|c|c|c|c|c|}
\hline \multirow{2}{*}{$\begin{array}{c}\text { Conflict } \\
\text { Involvement }\end{array}$} & \multicolumn{10}{|c|}{ Trial } & \multirow[t]{2}{*}{ Average } \\
\hline & 1 & 2 & 3 & 4 & 5 & 6 & 7 & 8 & 9 & 10 & \\
\hline Less & 474.7 & 472.0 & 475.2 & 471.3 & 474.8 & 474.4 & 474.5 & 473.9 & 474.8 & 473.3 & 473.9 \\
\hline Moderate & 4.6 & 6.8 & 4.0 & 6.8 & 4.5 & 4.5 & 4.7 & 5.3 & 4.0 & 5.1 & 5.0 \\
\hline High & 0.8 & 1.3 & 0.8 & 1.9 & 0.8 & 1.1 & 0.8 & 0.8 & 1.3 & 1.0 & 1.1 \\
\hline
\end{tabular}


The model-simulation result for 50\% pragmatic legitimacy (Table 3) shows that still majority of the employee's needs are not into conflict $(\mathrm{M}=455.3)$ by the central authority of the organization. However, compared to previous degree of pragmatic legitimacy, numbers of employees who are moderately into conflict $(M=19.6)$ and in actual conflict $(M=5.2)$ are starting to increase. This simulation relates to Weber's legalrational authority which manifests the power of the bureaucracy over the individual.

The result (Table 3) could mean that pragmatic legitimacy at this degree is now more legal and rational compared to the $90 \%$ and $75 \%$ pragmatic legitimacy. This time, the mode of responding to the felt needs of the employees are procedural and are based laws bestowed upon the central authority (Maboloc, 2015). In this degree of pragmatic legitimacy, the degree of responding to the employee's need is embodied in formal bureaucracy, the rule of law, the appeal to efficiency, and the rational fit between means and intended goals (Coleman, nd). Contemporary organization followed to this degree of pragmatic legitimacy. As the complexities of employees felt need arises, there is a need of a bureaucracy that embodies order and systematization to sustain legitimacy in the organization. However, while order and systematization are desirable, the central authority may not be able to fully address the problems and concerns of everyone, as what the development of organizations today suggests (Maboloc, 2015). Thus, conflict is not avoidable but can be managed.

Table 3: Simulation results for $50 \%$ organization pragmatic legitimacy

\begin{tabular}{|c|c|c|c|c|c|c|c|c|c|c|c|}
\hline \multirow{2}{*}{$\begin{array}{c}\text { Conflict } \\
\text { Involvement }\end{array}$} & \multicolumn{9}{|c|}{ Trial } & Average \\
\cline { 2 - 13 } & $\mathbf{1}$ & $\mathbf{2}$ & $\mathbf{3}$ & $\mathbf{4}$ & $\mathbf{5}$ & $\mathbf{6}$ & $\mathbf{7}$ & $\mathbf{8}$ & $\mathbf{9}$ & $\mathbf{1 0}$ & \\
\hline Less & 457.8 & 455.8 & 457.2 & 448.7 & 454.8 & 455.8 & 455.8 & 451.8 & 457.1 & 458.4 & 455.3 \\
\hline Moderate & 17.2 & 19.8 & 17.8 & 23.9 & 20.0 & 19.2 & 19.7 & 22.1 & 19.1 & 17.1 & 19.6 \\
\hline High & 5.1 & 4.5 & 5.1 & 7.4 & 5.3 & 5.1 & 4.6 & 6.2 & 3.8 & 4.5 & 5.2 \\
\hline
\end{tabular}

Generally, the model shows that pragmatic legitimacy order guided organizational interaction. This assumption is well-illustrated by the result of the model-simulation depicting the functional relation between pragmatic legitimacy and the employees' conflict involvement. It can de deduced from the simulation that the zero-violence due to high degree of employees' felt need satisfaction does not really reflect an ideal pragmatic legitimacy as discussed in Table 2. Reality shows that felt need of employees are multiple in nature and, as the complexities of employees felt need arises, there is a need of a bureaucracy that embodies order and systematization to sustain legitimacy in the organization. In the actual arena, the model-simulation suggests that the strength of the pragmatic legitimacy does not depend only on the number of employee who are not involved into conflict but also on the degree on which the organization was able to control that complex need of each employee which leads to their satisfaction (Figure 1).

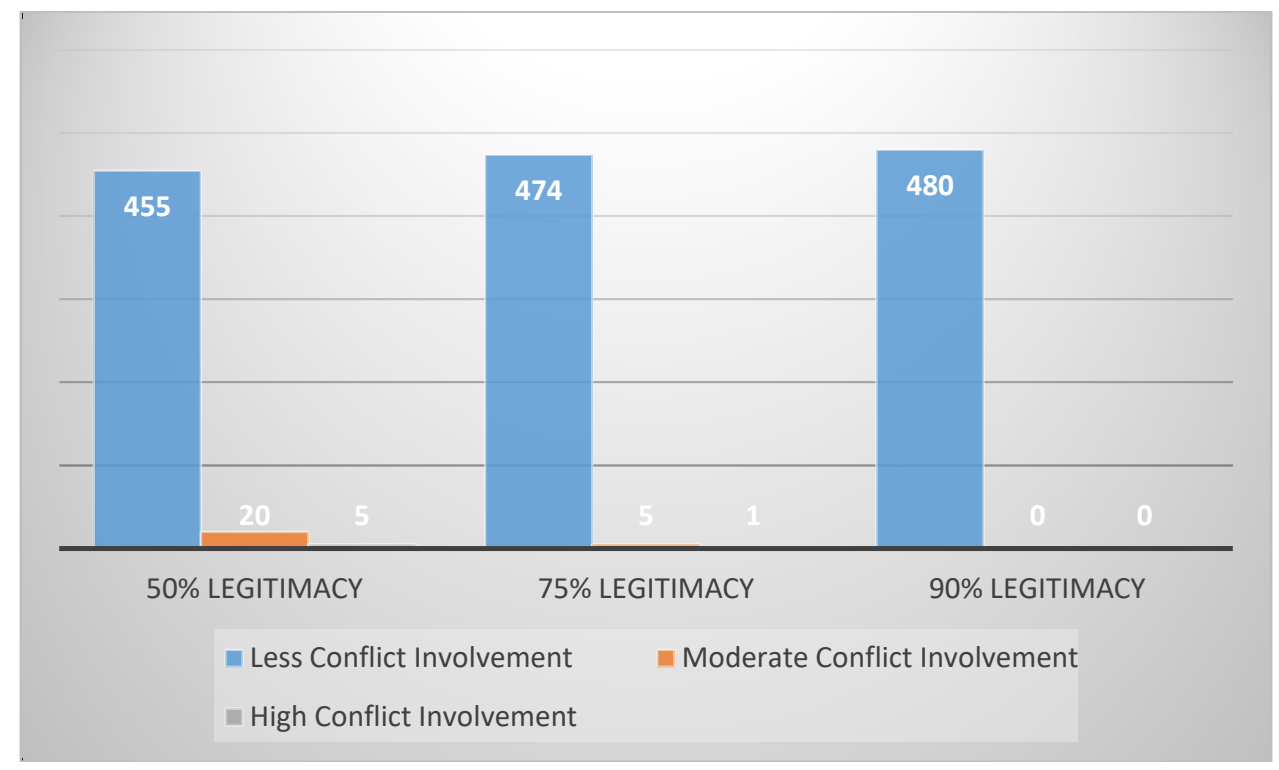

Figure 1. Comparison of employees' conflict involvement vis-à-vis degree of perceived pragmatic legitimacy 
For Suchman (1995), legitimacy was attained because of frequent and intense communication with the organization's social surroundings. In this case, the model illustrates close proximity between supervisor and the subordinates which allows deeper communication which leads to organizational adjustment and adaptation (Everet, 2001). As such, organizations that monitor and respond to display of employees' perceptions and behaviour maximize the achievement of pragmatic legitimacy (Assumption 2). To this effect, a company would voluntarily report on activities if management perceived that those activities were expected by the employees in which it operates (Deegan, 2002; Deegan, Rankin \& Voght, 2000; Cormier \& Gordon, 2001).

Result of the simulation, moreover, conferred with the universal claim that organizational legitimacy is not only controlled by entities outside the organization but also on the effort of the organization to maintain a coalition of supportive and active employees (Pfeffer \& Salancik, 1978) - agents that determines the power of legitimacy - by satisfying their felt needs. Legitimacy in the organization is, thus, attained by the display of positive response of employees whose felt need are properly addressed by the organization (Assumption 3). Such display reflects employees' high regard to the central authority's determination to meet their expectations (Aldrich \& Fiol, 1994). Organizations that adhere to societal expectations, and that build an ongoing reputation for their appropriateness and correctness are viewed as trustworthy and reliable, which contribute to being accorded legitimacy (Brinlerhoff, 2005). Finally, this paper argued that the degree of pragmatic legitimacy of authority plays a significant role in determining organization behaviour and structure. This would minimize or even eradicate the problem on "persistent performance differences" among employees across organizations due to unmet needs.

\section{CONCLUSION}

The Model on Pragmatic Legitimacy increases the exchange of relationship between an organization and its constituents. Decrease in pragmatic legitimacy reduces welfare and provides higher probability of organizational conflict. Yet, the strength of the pragmatic legitimacy does not depend only on the number of employee who are satisfied but also on the degree on which the organization was able to control that complex need of each employee which leads to their satisfaction. Thus, for pragmatic legitimacy to be beneficial, the organization must direct less in specific benefits for an individual employee and, instead, more responsive to the employees' larger interest.

\section{REFERENCES}

[1]. Aldrich HE. (1979). Organizations and environments. Englewood Cliffs, NJ: Prentice-Hall.

[2]. Aldrich, H. E., \& Marsden, P. (1988). Environments of organizations.

[3]. Benyishay, A., Brooks, J., Castañeda, R., Fort, T., Locay, L., Rajan, R., ... Wallis, J. (2012). LEGITIMACY \& DEMOCRACY: BASIC CONCEPTS WITH AN APPLICATION TO THE HONDURAN 2009 CRISIS . Roger R. Betancourt * Legitimacy \& Democracy : Basic Concepts with an Application to the Honduran 2009 Crisis . Abstract, (July 2011).

[4]. Brinkerhoff, R. O. (2005). The Success Case Method: A Strategic Evaluation Approach to Increasing the Value and Effect of Training. Advances in Developing Human Resources, 7(1), 86-101. http://doi.org/10.1177/1523422304272172

[5]. Buysse, K., Verbeke, A., Strategic, S., Journal, M., May, N., Wiley, J., ... Verbeke, A. (2010). Proactive Environmental Strategies : a Management Perspective Stakeholder, 24(5), 453-470.

[6]. Cho, C. H. (2007). Organisational Legitimacy and the atrategic use of accounting information: three studies related to Social and Environmental Disclosure, 157. Retrieved from http://etd.fcla.edu/CF/CFE0001555/Cho_Charles_H_200705_PhD.pdf

[7]. Cho, C. H., Patten, D. M., \& Roberts, R. W. (2006). Corporate political strategy: An examination of the relation between political expenditures, environmental performance, and environmental disclosure. Journal of Business Ethics, 67(2), 139-154.

[8]. Cuganesan, S., Ward, L., \& Guthrie, J. (2007). Legitimacy theory: A story of reporting social and environmental matters within the Australian food and beverage industry. ... Interdisciplinary Research in ..., 1-35. Retrieved from http://papers.ssrn.com/sol3/papers.cfm?abstract_id=1360518

[9]. Deegan, C., Rankin, M., \& Tobin, J. (2002). An examination of the corporate social and environmental disclosures of BHP from 1983-1997: A test of legitimacy theory. Accounting, Auditing \& Accountability Journal, 15(3), 312-343.

[10]. DiMaggio Paul J., P. (n.d.). The Iron Cage Revisited: Institutional Isomorphism. http://doi.org/10.2307/2095101

[11]. DiMaggio, P. J., \& Powell, W. W. (Eds.). (1991). The new institutionalism in organizational analysis (Vol. 17). Chicago, IL: University of Chicago Press.

[12]. Epstein, J. M. (2002). Modeling civil violence: an agent-based computational approach. Proceedings of the National Academy of Sciences of the United States of America, 99(3), 7243-7250. 
http://doi.org/10.1073/pnas.092080199

[13]. Eroglu S., Toprak S., Urgan O, MD, Ozge E. Onur, MD, Arzu Denizbasi, MD, Haldun Akoglu, MD, Cigdem Ozpolat, MD, Ebru Akoglu, M. (2012). Organization Evolving. Saudi Med J (Vol. 33). http://doi.org/10.1073/pnas.0703993104

[14]. Etzioni, A. (1987). Entrepreneurship, adaptation and legitimation: a macro-behavioral perspective. Journal of Economic Behavior \& Organization, 8(2), 175-189.

[15]. Handaru, A. W., \& Carolina, C. (2013). Motivational Factors, Entrepreneurship, Gender, and Parental Background: Evidence From the Tailor's Guild at Sunan Giri Traditional Market, Jakarta, Indonesia, 12(6), 627-635.

[16]. Hannan, M. T., \& Freeman, J. (1989). Organizations and social structure. Organizational ecology, 3-27.

[17]. Hegtvedt, K. A. (2004). Review essay: Legitimizing legitimacy: Shaping a new Frontier of research. Social Justice Research, 17(1), 93-109.

[18]. Hodgson, J. P. E. (1986). Interactive problem solving. ACM SIGART Bulletin, (98), $22-24$. http://doi.org/10.1145/15923.15925

[19]. Huppert, T. (n.d.). Max Weber: Finding Significance in Reality, 1-21.

[20]. Ingersoll, R. M. (2001). Teacher Turnover, Teacher Shortages , and the Organization of Schools by ctp Center for the Study of Teaching and Policy Center for the Study of Teaching and Policy, 2001(January).

[21]. Jost, J. T., \& Major, B. (2001). Emerging perspectives on the psychology of legitimacy. The Psychology of Legitimacy. Emerging Perspectives on Ideology, Justice, and Intergroup Relations, 3-31.

[22]. Milne, M. J., \& Patten, D. M. (2002). Securing organizational legitimacy: An experimental decision case examining the impact of environmental disclosures. Accounting, Auditing \& Accountability Journal, 15(3), 372-405.

[23]. Monti, G. (2005). The importance of, (October), 18-20. http://doi.org/10.1053/j.jrn.2009.05.003

[24]. Mousa, G. A., \& Hassan, N. T. (2015). Legitimacy Theory and Environmental Practices : Short Notes, $1(1)$

[25]. Patel, A. M., Xavier, R. J., \& Broom, G. (2005). Toward a model of organizational legitimacy in public relations theory and practice. Proceedings International Communication Association Conference, 1-22. Retrieved from http://eprints.qut.edu.au/10132/

[26]. Pfeffer, J., \& Salancik, G. R. (1978). The external control of organisations. New York, 175

[27]. Ruef, M., \& Scott, W. R. (1998). A multidimensional model of organizational legitimacy: Hospital survival in changing institutional environments. Administrative science quarterly, 877-904.

[28]. Scott, W. R., Ruef, M., Mendel, P., \& Caronna, C. A. (2000). Institutional change and organizations: Transformation of a healthcare field. Chicago: University of Chicago.

[29]. Suchman, M. C. (1995). Managing legitimacy: Strategic and institutional approaches. Academy of management review, 20(3), 571-610.

[30]. Tilling, M. V. (2004). Refinements to Legitimacy Theory in Social and Environmental Accounting Not One Theory but Two ( at least ). Commerce Research Paper Series, 06(04), 1-11.

[31]. Xavier, Robina J . and Johnston, Kim A . and Patel, Amisha M . ( 2005 ) Operationalising Strategy : An Evaluation of Strategy in Public Relations Campaigns . In Purchase, Sharon, Eds . Proceedings Australia New Zealand Marketing Academy Conference , . (2005), 180-186.

[32]. Weber, M. (1947). Legitimate authority and bureaucracy. The theory of social and economic organisation, 328-340.

[33]. Zelditch, M. (2001). Theories of legitimacy. The psychology of legitimacy: Emerging perspectives on ideology, justice, and intergroup relations, 33 . 